\title{
Dementia citizenship: the need for dementia and gerontology education in hospice and palliative care
}

\section{Introduction}

There are few education fields that offer more than Sociology as far as being catalysts for social justice and better care for disenfranchised groups (e.g. elders and persons living with dementia etc.). Sociologists in the field of thanatology are interested in providing quality gerontological and dementia person centered education for hospice and palliative care administrators and service providers. This kind of pedagogy is especially needed in end of life dementia care because of the unique challenges persons living with dementia (PLWD) can present. American colleges offer a plethora of well-designed M.A. and M.S. Gerontology Masters programs online but they are usually lacking in dementia courses. Nevertheless, compared to MBA or business degree, these online Masters programs offer cutting edge gerontological education-including in most cases end of life care information and courses. Also, these Masters programs come under the umbrella of a variety of disciplines besides Sociology.

Getting the M.S. in Gerontology credential alone should be of interest for administrators of Hospice and Palliative Care programs. After all, the vast majority of care recipients are elders. But America is seeing a burgeoning number of elders and younger adults who suffer from severe dementia enter hospice and palliative care. Texas State University is the alma mater of the late President Lyndon Baines Johnson. He was the first President to formulate significant civil rights legislation in America. Now at President Johnson's alma mater the civil rights of persons living with dementia are championed and ageism is combated in the training of Hospice and Palliative Care Administrators with this dementia education program.

To honor means to place high value upon elders and PLWD. Dementia citizenship both as the phrase and as formal legislation in the United Kingdom, involves understanding how human rights are taken away on many occasions from dying persons with dementia (PLWD). One of many examples of how their rights can be taken away lies in the areas of family visitation in long term care and the lack of engaging activities being offered to end of life PLWD. With regard to family engagement, there is a general lack of family caregiver education in long term care. Add to this the lack of gerontology and dementia education among the formal caregiving staff in end of life (EoL) care. Elders who are bored and lonely often spend their days bedridden and hollering for attention with few attempts to engage them in sensory activities similar to Namaste and other kinds of EoL social activities and room modifications to engage them.

In America, when persons are given the label of "Alzheimer's disease (AD)" or "Lewy Body Disease (LBD)" and so forth, their social world often significantly diminishes. This social disengagement can happen even among the PLWD's nuclear family and primary group. Significant others feel that if the PLWD doesn't know them anymore what is the point of visitation? This is where family dementia education in long term care facilities is needed. Family care partners can be encouraged to engage their PLWD resident and loved one who is in hospice or palliative care with sensory activities (e.g. tapping into their long term memory with familiar foods, music, songs, pets, stuffed animals, pictures etc.); life is not over until it's over.

\author{
Volume 2 Issue 6 - 2018 \\ Christopher Jay Johnson \\ Texas State University, USA
}

Correspondence: Christopher Jay Johnson, $\mathrm{PhD}$, Texas State University, USA, Email gero9johnson@gmail.com

Received: July 26, 2017 | Published: November 27, 2018

There are prejudices and stigmas attached to PLWD and elders in general in America. It seems our country has enormous compassion and engagement with disabled children but when it comes to the disability of dementia, there is pronounced ageism. ${ }^{1}$ PLWD have a disability with abilities, even with severe dementia, we shouldn't give up on trying for social connections with them.

Stemming from the work of Kitwood " "personhood" or what we call "elderhood" has provided a foundation for renewed interest in providing new and fresh types of social connections with PLWD in end of life dementia services and research for over 15 years. It's touted by many people in the so-called "Culture Change" movement as the foundation of their unique approach to social change in end of life care. Yet as long as we are often running short on staff and supplies in long term care and the American turnover rates are what they are, there are few real social friendships and connections with end of life PLWD.

Dementia citizenship and combating ageism is a core value that should drive the course development for an M.S. in Dementia and Aging Studies program. After all we are preparing a philosophy of dementia citizenship and full human rights for students who want to be administrators in Hospice and Palliative care. But where the rubber meets the road is quality control of M.S. in Gerontology or Dementia and Aging Studies curriculum and hiring well trained faculty who are passionate about dementia citizenship, elder rights and is free of prejudice and stigma. Love is the foundation of all good care, persons who work with EoL elders must love older persons. Full human rights for persons with dementia (PLWD) will empower them and their care partners. When we embolden the PLWD by raising consciousness of compassionate care with family and staff, then we will see an elevation in the status of people living with severe dementia. A number of scholarly papers have shown that personhood of elders in long term care is mainly an apolitical concept. Person centered care which is built upon what the late American Carl Rogers called personhood and later applied to dementia care by Tom Kitwood ${ }^{2}$ in the UK, is concerned with psycho-social issues. Such concerns of simply looking at each of us as individuals with unique biographies, however, might be too limiting. So dementia citizenship provides another possible way to look at human rights, another lens. Citizenship is used in Sociology to promote the status of groups who are victims of prejudice and discrimination (e.g. women, Blacks, Native Americans, Elders etc.). We know that we must take this human rights perspective a step further for PLWD, these persons are entitled to the same human 
rights as everyone else. So as citizenship tends to assume an awareness to exercise rights and responsibilities, it isn't always appropriate for persons with severe dementia since their agency is limited.

Bartlett \& O'Connor ${ }^{3}$ point out that both personhood and dementia citizenship as concepts are problematic because they take too narrow a view of the human rights experience. For the field of Gerontology to develop over the next decade or two, we need a broader view that is more inclusive of personhood and dementia citizenship. We should employ sociological ideas about free will and the social construction of dementia to move our culture forward toward full inclusion of PLWD in our cities and towns. At the same time, also need to understand the dynamics of the current trends toward the commodification of dementia by the Memory Care industry. Here we see all too many cases of self-proclaimed dementia experts and shallow dementia certifying organizations which lack depth and breadth in educational substance have tried to jump on the dementia bandwagon without the depth and breadth of knowledge an M.S. in Dementia and Aging Studies degree can offer in both biological and sociological knowledge in this field. Sociology is interested in eliminating stigmas of end of life PLWD. Stigma of dementia begins early in America with all aspects of social discourse, including greeting cards and the media. All too often it's negatively associated with aging. So the public fears growing old, assuming it will only offer them dementia. Stigma can be caused by labels in dementia which create fear and stereotypes of PLWD. Such stigmas can cause many American families to disengage from their loved one with dementia especially if he or she doesn't recognize them. A recent article entitled, "Dementia at the End of Life and Family Partners: A Symbolic Interactionist Perspective on Communication" we used a time travel model to educate people to Alzheimer's disease (AD) and actually how it's not regression neatly through stages but instead a form of time travel where the PLWD revisits his or her sociological past. Toward the end the person is revisiting childhood and all the experiences of early childhood. So $\mathrm{AD}$ is not a "death certificate", an "ongoing funeral" or regression, its time travel. ${ }^{4,5}$

At Texas State University, where the late President Lyndon Baines Johnson went to school, he signed the Civil Rights Bill of 1964; it's a land mark in World History. So needless to say, human rights are a focus of our M.S. in Dementia and Aging Studies degree online. We follow the later President Johnson's lead as the one President in the U.S. who passed significant human rights laws, while dealing with his own prejudices. Yes, we need to examine how this culture creates them in us all. Our M.S. in Dementia and Aging Studies (MSDA) program, the first of its kind in the world (although there are 17 Dementia Studies programs in Europe, none give equal attention to both to my knowledge), embraces full human rights and respect for elders or "elderhood." Our entire MSDA online degree program in Sociology is about combating ageism and promoting human rights for persons with dementia. American materialists are always fighting aging or are anti-aging, instead of embracing our elderhood as we could and should be doing.

The late Maggie Kuhn, who organized the Gray Panthers organization in the States, was a major influence on de-mystifying the anti-aging movement in America for me. In 1980, Maggie told a group of Iowans for nursing home reform the reality of America. I was among some $\mathrm{PhD}$ grad students from Iowa State University gerontology program who came to listen to her speak. She said that ageism and lack of acceptance of who we are and whatever age we are is caused by deep prejudices against growing old and youth worship in a materialist American culture. Elders are told they "need" to use such and such product to look "younger" instead of embracing their wrinkles and gray hair as beautiful on its own accord. Ageism asks us as elders to reject who we are physically, which is not good. Maggie Kuhn would say, "I am an old woman and I am beautiful and sexy the way I am now, don't tell me I look young for my age." Over the years her wisdom has totally soaked in for me. We understand that "Culture Change" is indeed needed. Many positive steps besides our program by such personages as Dr. Bill Thomas, Dr. Allen Power and the entire personhood movement at Bradford University and the Stirling Universities in the UK are great. Although not research based enough, the Dementia Village in Holland is promising. Yet to be fair, real versus fake "Culture Change" will take time. We are headed in the right direction now. Realistically, it is not possible to have culture change with long term care having so little gerontological educational requirements for nursing home administrators (few states require any Gerontology credential like a M.A. or M.S. in Gerontology for example). We add to this the paucity of gerontological nursing education. For example, nurses (e.g. no gerontology or dementia education required) who work in long term care settings and CNA's (e.g. 75 hours of training and a test and poverty level wages in Texas vs. a year of training in Canada and middle class wages etc.) are truly in need of an upgrade in gerontological and dementia education and training. Lack of dementia and aging formal education among leadership of long term care facilities is the norm not the exception, such modus operandi are not indications of "culture change."

Of course, this isn't to say that the long term care industry isn't making strides toward improvement of education, training and care delivery. They are making some very significant changes. We are seeing more and more persons entering the M.S. in Dementia and Aging Studies or M.A. and M.S. in Gerontology long term care track programs. These people often have a strong desire to make a difference in EoL care. Yet, when nursing homes or assisted living facilities run over 100 turnover, whiling frequently keeping resident aides at impoverished living levels with very low wages, those are violations of human rights. Moreover, when we see inadequate training of CNA's or owners violating the human rights of both staff and residents by hindering their staffs from effectively carrying out their jobs by running short-handed on staff or supplies, then we have to assume a strong need for social change. One can only conclude from such practice, that there is little or no time for staff to get to know residents as persons; this removes full citizenship from PLWD.

Finally, as gerontologists with special training in the social model of care and evidence based environmental design for dementia, we also often see a lack of such evidence based dementia design features to many or maybe most Memory Care neighborhoods that are spring up everywhere. So one impartial observer can say things are getting better than a decade ago but we aren't ready to proclaim "Culture Change." So although we have a long way to go, Eden Alternative and Greenhouse Movements, Namaste and other exciting designs for living in full dignity with both elderhood and dementia citizenship is on the move toward significant social change!

\section{Acknowledgments}

None.

\section{Conflicts of interest}

The author declares there is no conflicts of interest. 